\title{
RESEARCH REPORT TREE-RING DATING OF SINMU-MUN, THE NORTH GATE OF KYUNGBOK PALACE IN SEOUL
}

\author{
WON-KYU PARK*, YO-JUNG KIM, JUNG-WOOK SEO ${ }^{1}$, and JIN-HO LEE \\ School of Forest Resources \\ Chungbuk National University \\ Cheongju 361-763, Republic of Korea \\ and

\section{TOMASZ WAZNY} \\ Institute for the Study, Conservation and Restoration of Cultural Heritage \\ Nicholas Copernicus University of Torun \\ Torun, 87-100, Poland
}

\begin{abstract}
The cutting dates of 10 wood timbers (girders and corner rafters) of Sinmu-mun, the north gate of Kyungbok Palace in Seoul, were determined by the dendrochronological method. Tree-ring chronologies of unknown dates derived from the timbers were crossdated using the graphic comparison method against the dated master chronologies derived from living trees. The living trees for the masters used for this study were Pinus densiflora Sieb. et Zucc. (Japanese red pine), a major timber species for Korean traditional buildings. By comparing the Sinmu-mun samples with the masters from the western Sorak Mountains in central-eastern Korea, the Sinmu-mun samples yielded the cutting dates A.D. 1868, 1869, and 1870/1871. Surprisingly, these dates are 3 to 6 year later than the known date (A.D. 1865) of the Sinmu-mun reconstruction, which was recorded in a historical document 'Ilsungrok', the King's official diary. Since the time that the Sinmu-mun construction date had been questioned, another record was found in the 1872 April issue of Ilsungrok, indicating the rebuilding of Sinmu-mun in the 1870 s. Both pieces of evidence, from tree-ring dates and historic records, prove that the rebuilding of Sinmu-mun started after the Fall of 1870, but not later than April 1872. The results prove that tree-ring dating is a precise dating method and it can be applied to archaeological studies on Korean structures.
\end{abstract}

Keywords: dendrochronology, cutting date, architectural history, Korea, Pinus densiflora.

\section{INTRODUCTION}

Some species growing in Korean forests have been reported to be several centuries old, thus providing unique opportunities to develop long tree-ring chronologies for dating buildings in this region (Park et al. 2001). Pinus densiflora Sieb. et Zucc. (Japanese red pine) occurs naturally in

*Corresponding author: treering@cbnu.ac.kr

${ }^{1}$ Present address: Division of Wood Biology, Department of Wood Science University of Hamburg, Hamburg, Germany.
Korea and Japan, although rarely in Manchuria, covering a wide ecological spectrum (Lee 1986). This species occupies nearly $40 \%$ of the forests of Korea, which cover about $65 \%$ of the total land area. The wood of this species was the most favored building material used in historical buildings in Korea and its dendrochronological potential has been explored (Park et al. 2001). As of 2006, the red pine chronologies from Korea extend to A.D. 1250 and have been used extensively for dating purposes in Korea. Here, 

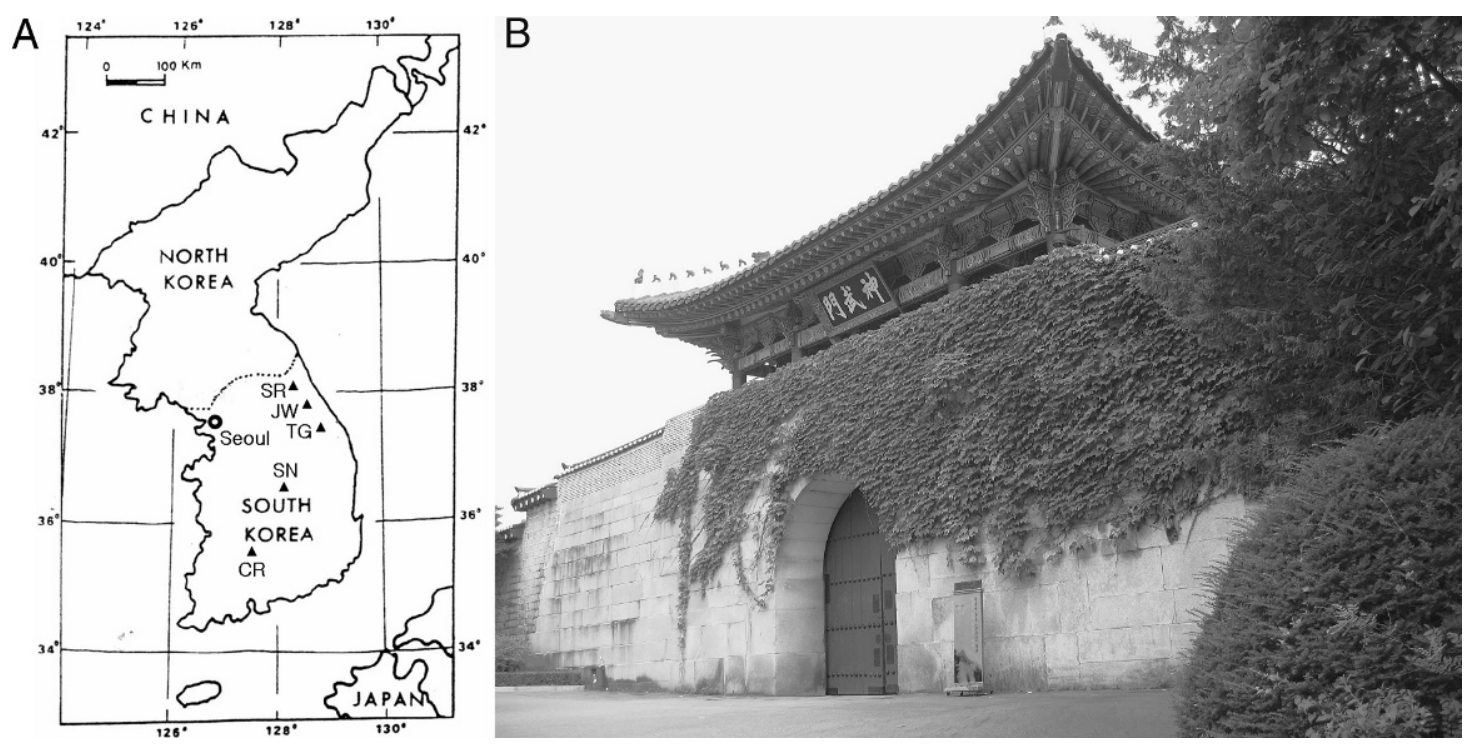

Figure 1. Left (A): Location of Sinmu-mun (Seoul) and the mountains for master chronologies of Pinus densiflora in South Korea (SR: Sorak, JW: Jewang, TG: Tongo, SN: Sogni, CR: Chiri mountains), Right (B): Sinmu-mun, the north gate of Kyungbok Palace in Seoul.

the first results of tree-ring dating in South Korea, of Sinmu-mun, a $19^{\text {th }}$ Century structure at Kyungbok Palace in Seoul (Fig. 1) are presented.

Sinmu-mun is the north gate of Kyungbok Palace, one of four existing palaces in Seoul, which was the capital city for over 500 years during the Chosun Dynasty (A.D. 1392-1910). Kyungbok Palace was originally constructed at the beginning of the Chosun Dynasty during the late $14^{\text {th }}$ Century. Kyungbok Palace was almost completely destroyed during the Korea-Japan war in 1592 and was reconstructed during the 1860s when Daewongun, the father of King Kojong, tried to reinforce royal authority. Ilsungrok, the Kings' diary of the Chosun Dynasty, records that the reconstruction of the Sinmu-mun gate was finished in 1865 (Jang 1963). After reconstruction of 1860s, however, Kyungbok Palace buildings experienced several fires and heavy destruction during the Japanese ruling period (1910-1945) and Korean War (19501953) (Lee 1998). Among the four main gate buildings in Kyungbok Palace, Sinmu-mun is known to be the only gate building to survive the Korean War. Therefore, it was necessary to clarify the construction date of Sinmu-mun, hypothesized to be the original one built in 1865 .

\section{METHODS AND MATERIALS}

During the period of repair of Sinmu-mun in 1999-2000, 10 wood elements or timbers were collected for dating by the authors. All sampled wood timbers were made from Japanese red pine. Wood discs (about $2 \mathrm{~cm}$ thick) were cut from the girders and corner rafters that had been removed and replaced due to partial decay. After sanding the surfaces of the sampled discs, ring widths were measured to the nearest $0.01 \mathrm{~mm}$ by using a Velmex measuring system. Ring-width plots of individual samples were produced by using the TSAP program (Rinn 1996). These plots were used for visual comparison on a light table to crossdate each other by synchronizing the patterns. Figure 2 shows the plots of the samples after synchronizing. A site chronology was made by averaging the data from all samples.

The final dating process was performed by graphic comparison between ring-width plots derived from the old wood timbers collected from the building 'Sinmu-mun' and those of master chronologies developed from living pine trees in several regions of South Korea (Park et al. 2001, Fig. 1). The dating quality was evaluated by statistical methods, $t$ and $G$ values. $T$ value (a measure of 


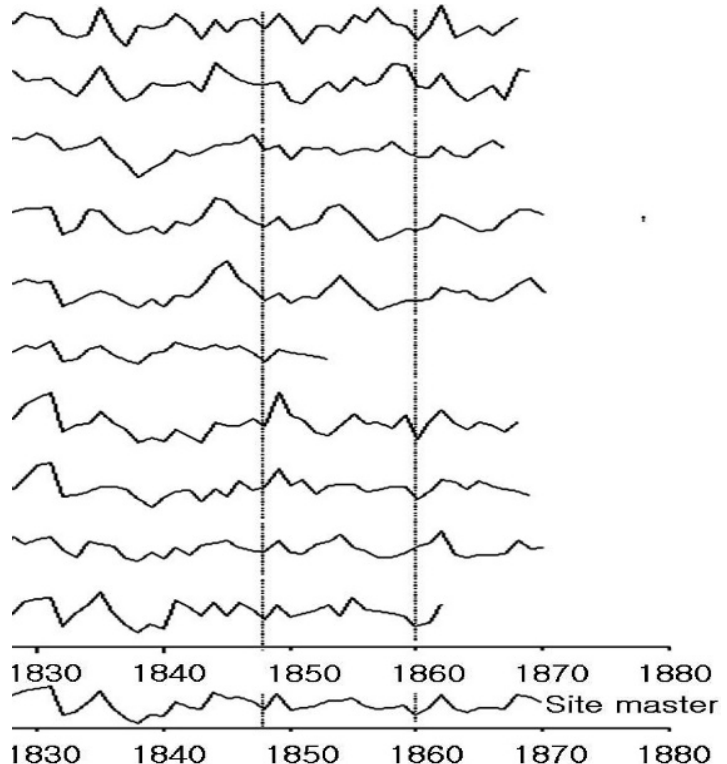

Figure 2. Construction of the site chronology (lowest one) by synchronizing the ring-width patterns of Sinmu-mun samples (the inner parts of the plots are truncated) (Y-axis: ring widths in $\log$ scale).

correlation between sample and master chronologies) is calculated with correlation coefficient (r) after detrending the chronologies by 5 -year moving averages (Baillie and Pilcher 1973) according to the equation $t=r \times(n-2)^{1 / 2} \div\left(1-r^{2}\right)^{1 / 2}$, where $\mathrm{n}=$ number of years. $\mathrm{G}$ value (Gleichlaufigkeit; sign agreement) was obtained after Eckstein and Bauch (1969).

\section{RESULTS}

The site chronology from Sinmu-mun crossdated well with the red pine chronology of the west-region sites of Mt. Sorak (named 'West Sorak' in Table 1) in eastern Korea, which were obtained from Hangaerung Pass in the Sorak at about $800-900$ m a.s.1.. The 'West Sorak' master chronology is 317 years (A.D. 1682-1998) long and is described in the previous paper (Park et al. 2001, p. 792). The east-region sites of Mt. Sorak, as well as all other pre-existing red pine chronologies from four mountain ranges in South Korea (Park et al. 1991), could not be crossdated with the Sinmu-mun chronology (Fig. 1 and Table 1). The Hangaerung Pass chronology possessed the highest correlation with that of Sinmu-mun ( $t$ value: 10.6 and $G$ value: $81 \%$ with 132-year overlap between Hangaerung and Sinmu-mun chronologies). The high $t$ and $\mathrm{G}$-values (sign agreement) suggest that the origin of Sinmu-mun timbers could be near Hangaerung, on the western region of Mt. Sorak. Hangaerung is close to the upper tributary of the Han River, along which the logs could be transported by rafting more than $200 \mathrm{~km}$ to Seoul. Rafting was one of the major transport methods used for logs in Korea during the preindustrial period (Jang 1963). A historic document, 'Reconstruction Record of Kyungbok Palace' also mentioned Inje port near Hangaerung as one of major suppliers for large-size logs (Jang 1963). However, denser networks of tree-ring data are needed to determine the logging sites.

The cutting dates of individual Sinmu-mun samples are given in Table 2. Based on the stage of earlywood/latewood formation recorded in the last ring with the bark, the cutting season as well as the cutting year were obtained. The cutting periods for the logs were from A.D. 1868 summer to 1871 spring (Table 2). Surprisingly, these dates are 3 to 6 years later than the recorded date for reconstruction of Sinmu-mun in 1865, which was known from the royal document Ilsungrok. Most Korean architectural historians were doubtful about these tree-ring dates (dendrochronology itself indeed) because the results from tree-ring dating did not match the dates recorded in the royal archive. One and a half years after we first

Table 1. The results of crossdating between Sinmu-mun chronology and master (reference) chronologies of living red pines in South Korea (see Fig. 1 for the locations of mountains).

\begin{tabular}{lcccccc}
\hline Mountains & East Sorak & West Sorak & Jewang & Sogni & Tongo & Chiri \\
\hline TVBP & 4.7 & 10.6 & 2.4 & 4.4 & 3.4 & 2.5 \\
G $(\%)$ & 70 & 81 & 54 & 66 & 60 & 65 \\
\hline
\end{tabular}

TVBP: t value calculated after Baillie and Pilcher (1973), G: Gleichlaufigkeit (sign test). 
Table 2. The results of crossdating for the Sinmu-mun samples.

\begin{tabular}{lrrrcrl}
\hline Sample No. & OVL & TVBP & G $(\%)$ & Years of Rings & Bark & Felling Year \& Season \\
\hline SINMU01 & 128 & 7.8 & 73 & $1741-1868$ & WKL & Fall 1868 to Spring 1869 \\
SINMU02 & 99 & 7.4 & 75 & $1771-1870$ & WKE & Summer 1870 \\
SINMU03 & 107 & 10.4 & 74 & $1761-1868$ & WKE & Summer 1868 \\
SINMU07 & 120 & 4.3 & 69 & $1751-1870$ & WKL & Fall 1870 to Spring 1871 \\
SINMU08 & 120 & 3.9 & 65 & $1751-1870$ & WKL & Fall 1870 to Spring 1871 \\
SINMU09 & 115 & 9.1 & 76 & $1739-1853$ & - & Some time after 1853 \\
SINMU11 & 93 & 7.0 & 76 & $1776-1869$ & WKE & Summer 1869 \\
SINMU13 & 100 & 4.1 & 66 & $1770-1869$ & WKL & Fall 1869 to Spring 1870 \\
SINMU14 & 128 & 5.3 & 65 & $1743-1870$ & WKL & Fall 1870 to Spring 1871 \\
SINMU16 & 105 & 8.3 & 78 & $1758-1862$ & - & Some time after 1862 \\
\hline
\end{tabular}

TVBP and G values were explained in Table 1. WKL: complete latewood band with the bark. WKE: incomplete earlywood band with the bark. OVL: overlapped period (years) between master and sample chronology (incomplete rings were not considered).

raised the question regarding the Sinmu-mun construction date determined from dendrochronological dating at the annual meeting of Korean Association of Architectural History (Park 2001), another record was found in the 1872 April issue of Ilsungrok, which indicated the 'rebuilding' of Sinmu-mun in the 1870s. The original content mentioned as "Additional budget should be supplied to complete the rebuilding of Sinmumun", assuring that the Sinmu-mun was being rebuilt before April 1872. The combined evidence of tree-ring dates and historic record provides conclusive proof that the rebuilding of Sinmu-mun started after the Fall of 1870, but not later than April 1872. It indicates there must have been another period of building activity in the 1870 s, after the initial 1865 reconstruction of Sinmumun. The reason for rebuilding this gate just 5 to 7 years after reconstruction (A.D. 1865) has not yet been revealed.

The term 'rebuilding' in Korean historical document is ambiguous and often means either reconstruction or remodeling. Because we could only collect samples from the timbers replaced during 1999-2000 repair of the Sinmu-mun, it was difficult to determine the scope of the 'rebuilding' recorded in Ilsungrok. However, it must be rather large because the cutting dates were obtained from major load-bearing timbers such as corner rafters and girders. It is still possible that Sinmu-mun gate was completely rebuilt in the early1870s. To clarify the scope of rebuilding, a further comprehensive survey of the building using tree-ring dating would be necessary. Although historical documentation could produce important information of building history, it often fails to explain the details of construction activities. Tree-ring dating could fill this gap. The results indicate that Sinmu-mun gate, which was rebuilt in the 1870s, has survived the heavy destruction of Kyongbok Palace's other buildings by both the Japanese ruling government during the early 20th Century and the Korean War in the 1950s.

\section{CONCLUSIONS}

The reconstruction date of the Sinmu-mun gate at Kyungbok Palace in Seoul was determined using Japanese red pine chronologies. The tree-ring series of Sinmu-mun timbers crossdated well with the red pine chronologies from the western part of Sorak Mountains, yielding the cutting dates of A.D. $1868-1870 / 1871$. These dates are 3 to 6 years later than the known reconstruction of Sinmu-mun in 1865, indicating that the rebuilding of Sinmumun must have been done within 5-7 years after the completion of the reconstruction of 1865 . The treering dates were supported by a newly found record by the royal document Ilsungrok. The provenance of the logs, determined by tree-ring dating, suggests that they could have been transported from the eastern part of Korea, about $200 \mathrm{~km}$ from Seoul, probably by rafting along the Han River. Successful dating of a 19th Century building also enabled the extension of multiple red pine chronologies by about 100 years, i.e. back to the early 1700s. 
The results from Sinmu-mun convinced Korean architectural historians and restorers of the accuracy of tree-ring dating and that they should not hesitate to include dendrochronological methods in architectural surveys for historic buildings, which are routinely conducted during restoration or repair. Since the completion of the Sinmu-mun project, more than 40 buildings have been dendrochronologically dated in Korea. Successful dating ensured that the tree-ring dating method is finally included in the official specifications for restoration by the Korea Cultural Heritage Administration (KCHA 2005).

\section{ACKNOWLEDGMENTS}

This work was supported by Korea Science \& Engineering Foundation grant no. R01-2000-00000393-0. Master chronologies were offered by Tree-Ring Material Bank (Chungbuk National University) supported by Korea Ministry of Science and Technology. We thank Dr. Frank W. Telewski (Michigan State University) for his help on editing and improving the manuscript. We also thank Hyun-Chae Lee and Hyun-Min Jeong for their technical assistance, Wang-Hee Park (Korea Cultural Heritage Administration) for providing the wood samples of Sinmu-mun and
Cheol-Hyeon Kim (Kyungbok Palace, KCHA) for the photo used in Figure 1.

\section{REFERENCES CITED}

Baillie, M. G. L., and J. R. Pilcher, 1973. A simple crossdating program for tree-ring research. Tree-Ring Bulletin 33:7-14.

Eckstein, D., and J. Bauch, 1969. Beitrag zu rationalisierung eines dendrochronologischen verfahrens und $\mathrm{zu}$ analyse seiner aussagesicherheit. Forstwis. Centralbl. 88:230-250.

Jang, D. W., 1963. A note about the reconstruction of Kyungbok Palace. Hyangto Seoul 16(7):7-58 [in Korean.]

Korea Cultural Heritage Administration, 2005. Guidelines for Restoration of Cultural Properties. Sinkwangsa Press, Daejeon, Korea; 343 pp. [in Korean.]

Lee, K. G., 1998. Kyungbok Palace. Daewonsa, Seoul; 143 pp. [in Korean.]

Lee, Y. N., 1986. Korean Coniferae. Ewha Womans University Press, Seoul [in Korean.]

Park, W.-K., Y. J. Kim, J. H. Lee, and J. W. Seo, 2001. Development of tree-ring chronologies of Pinus densiflora from Mt. Sorak and dating the year of construction of the Kyunghoe-ru pavilion in Seoul. Journal of Korean Physical Society 39(4):790-795.

Park, W.-K., 2001. A new tool for the study of architectural history. In Proceedings of 2001 Annual Meeting of Korean Association of Architectural History, edited and published by Korean Association of Architectural History, pp. 21-25. Seoul, Korea.

Rinn, F., 1996. TSAP version 2.4-Reference Manual. Frank Rinn Co., Heidelberg; 187 pp.

Received 15 January 2007; Accepted 23 July 2007. 